\title{
Nutritional management of gut health in pigs around weaning
}

\author{
Jean-Paul Lallès ${ }^{1 *}$, Paolo Bosi ${ }^{2}$, Hauke Smidt ${ }^{3}$ and Chris R. Stokes ${ }^{4}$ \\ ${ }^{1}$ INRA, UMR1079, Rearing Systems, Animal and Human Nutrition, F-35590 Saint-Gilles, France \\ ${ }^{2}$ Diproval, University of Bologna, Reggio Emilia, Italy \\ ${ }^{3}$ Laboratory of Microbiology, Wageningen University, Wageningen, The Netherlands \\ ${ }^{4}$ Veterinary Pathology Infection \& Immunity, University of Bristol, Langford, UK
}

\begin{abstract}
Early weaning of piglets is often accompanied by a severe growth check and diarrhoea. It is well established that this process is multi-factorial and that post-weaning anorexia and undernutrition are major aetiological factors. Gastrointestinal disturbances include alterations in small intestine architecture and enzyme activities. Recent data indicate transiently-increased mucosal permeability, disturbed absorptive-secretory electrolyte balance and altered local inflammatory cytokine patterns after weaning. These responses appear to operate according to two distinct temporal patterns, an acute response followed by a long-lasting adaptation response. Pigs coexist with a diverse and dense commensal microbiota in their gastrointestinal tract. Most of these microbes are beneficial, providing necessary nutrients or protection against harmful pathogens for the host. The microbial colonisation of the porcine intestine begins at birth and follows a rapid succession during the neonatal and weaning period. Following the withdrawal of sow's milk the young piglets are highly susceptible to enteric diseases partly as a result of the altered balance between developing beneficial microbiota and the establishment of intestinal bacterial pathogens. The intestinal immune system of the newborn piglet is poorly developed at birth and undergoes a rapid period of expansion and specialisation that is not achieved before early (commercial) weaning. Here, new insights on the interactions between feed components, the commensal microbiota and the physiology and immunology of the host gastrointestinal tract are highlighted, and some novel dietary strategies are outlined that are focused on improving gut health. Prebiotics and probiotics are clear nutritional options, while convincing evidence is still lacking for other bioactive substances of vegetable origin.
\end{abstract}

Pig: Weaning: Diet: Intestine

Gastrointestinal disturbances immediately post weaning cause large economic losses in the pig industry. Within the pig population total losses of all those born in the EU amount to approximately $17 \%$ and a substantial proportion of these losses can be associated with infections via mucosal surfaces. Throughout Europe it is normal commercial practice that pigs are weaned at a much earlier age than they would in the wild, which results in an increased susceptibility to infection.

The weaning transition is a complex period during which the piglets have to cope with abrupt separation from their mother, mixing with other litters in a usually new environment, and switch from highly-digestible (liquid) milk to a less-digestible more-complex solid feed. Weaning at an early age (21-35d), as in intensive production systems, has probably exacerbated the level of general stress in these immature animals. Weaning is usually associated with low and variable feed (and water) intake resulting in a transient growth check (for review, see Pluske et al. 1997). Although 50\% of weaned piglets consume their first meal within $24 \mathrm{~h}$ post weaning, $10 \%$ have not eaten until $\geq 48 \mathrm{~h}$ (Brooks et al. 2001). Thus, energy requirements for maintenance are only met $3 \mathrm{~d}$ post weaning, and it can take 8-14 d for piglets to recover their preweaning level of energy intake (Le Dividich \& Sève, 2000).

Various nutritional approaches for optimising the weaning transition and minimising enteric diseases have been tested in the past decade. For example, much work has been done on organic acids, some of which, alone or in

\footnotetext{
Abbreviations: ETEC, enterotoxigenic Escherichia coli; GIT, gastrointestinal tract; SPD, spray-dried plasma; VFA, volatile fatty acids; VFI, voluntary feed intake.

*Corresponding author: Dr Jean-Paul Lallès, fax + 3322348 5080, email Jean-Paul.Lalles@ rennes.inra.fr
} 
combination, clearly contribute to animal health, mostly through acidification of the gastrointestinal tract (GIT) environment and/or control of potentially-pathogenic bacteria (Mroz, 2003). Medium-chain TAG have also provided positive responses in pigs, but mechanisms remain to be explored further (Decuypere \& Dierick, 2003).

The present review focuses on recent insights into GIT physiology, microbiology and immunology as a basis for nutritional management of GIT health in pigs around weaning.

\section{Physiology, microbiology and immunology of the gastrointestinal tract around weaning}

\section{Physiology}

The intestines display various functions including absorption of nutrients, absorption and secretion of electrolytes (and water), secretion of mucin and immunoglobulins and selective barrier protection against harmful antigens and pathogens (for review, see Lallès et al. 2004). Postweaning changes in intestinal tissue, including changes in villus and crypt architecture and depressed activities of many brush-border digestive enzymes, have been well documented and the implication of the presence of pathogens (Escherichia coli, rotaviruses) has also been addressed (Pluske et al. 1997). Many changes in intestinal physiology occur during the 2 weeks post weaning (Boudry et al. 2004). Transient increases in net ion transport in the jejunum and colon and in glucose absorption capacity in the jejunum and decreased jejunal electric resistance have been documented in piglets fasted for $2 \mathrm{~d}$ after weaning (Boudry et al. 2004). Preweaning values are usually observed again at $5 \mathrm{~d}$ after weaning. However, long-lasting changes are also recorded up to 2 weeks after weaning. Jejunal glucose absorption and secretory responses to secretagogues decrease while ileal transmucosal electric resistance increases on day 5 post weaning and then stabilise. Permeability to macromolecules across the jejunum decreases on day 2 post weaning and remains low thereafter. Thus, weaning induces transient acute changes probably related to post-weaning fasting, followed by a period of intestinal maturation corresponding to voluntary feed intake (VFI) resumption.

\section{Microbiology}

The gut is sterile at birth and is then colonised by microbes from the mother and the environment, starting with lactic acid bacteria, enterobacteria and streptococci. After the introduction of solid feed obligate anaerobes increase in number and diversity until an adult-type pattern is achieved (Inoue et al. 2005; Konstantinov et al. 2006a). The commensal microbiota salvage energy from otherwise indigestible carbohydrates and protect the host from pathogens by forming a front line of mucosal defence (Zoetendal et al. 2004). In contrast to adults the neonatal and weaning piglet is highly susceptible to enteric diseases (Hopwood \& Hampson, 2003). In the immediate postweaning period the balance between the development of so-called healthy commensal microbiota and the establishment of a bacterial intestinal disease can be easily tipped towards disease expression (Hopwood \& Hampson, 2003). Piglets weaned within a 'production' environment experience major changes in intestinal microbiota composition that are influenced by diet, environmental factors and the host (Konstantinov et al. 2004b). In a short period of time the intestinal microbiota must ultimately develop from a simple unstable community into a complex and stable community, thus generating a tight 'colonisation resistance' or 'competitive exclusion'.

It is recognised that microbial fermentation within the GIT is very important for the pig (Williams et al. 2001). The main products of fermentation include volatile fatty acids (VFA), which are known to play an important role in water $\left(\right.$ and $\mathrm{Na}^{+}$) absorption, $\mathrm{pH}$ control and the inhibition of pathogens. In relation to host GIT health, fermentation (i.e. microbial activity) is also important for gut motility, improvement of energy yield, vitamin production and the stimulation of gut immunity. It is also involved in the prevention of diarrhoea and defence against pathogens (colonisation resistance; van der Waaij et al. 1971). The composition of the diet is crucial in determining the composition and activity of the intestinal microbiota, and thus the production of the VFA mixture and other end products that will be optimal to gut health. For example, there is an important difference between the fermentation of carbohydrates and protein. Fermentation of carbohydrates leads to the production of mainly straight-chain VFA (e.g. acetic, propionic and butyric acids) and the use of $\mathrm{NH}_{3}$ and other nitrogenous compounds, which are required for microbial growth. When carbohydrates are in short supply relative to the available protein of non-degradable and endogenous origin, protein will be used as an energy source for fermentation, resulting in the end products $\mathrm{NH}_{3}$, branchedchain VFA and potentially toxic end products (Williams et al. 2001). These compounds include amines, volatile phenols and indoles (Visek, 1978; Yokoyama et al. 1982; Russell et al. 1983; MacFarlane et al. 1992).

\section{Immunology}

The piglet is immunodeficient at birth and is highly dependent on a supply of specific and non-specific immune factors present in maternal colostrum and milk for immune protection, development and survival. The functional immaturity of the immune systems is such that newborn pigs are only able to generate limited $\mathrm{T}$ - and B-cell responses when challenged with pathogens, thus contributing to their immuno-compromised state (Butler et al. 2000). Clearly, development of immuno-competence is an absolute requirement for optimum growth and performance. However, in the context of exposure to a wide range of antigens associated with pathogens and with commensal bacteria and food, immuno-competence can be defined as the ability to mount appropriate responses to antigens, including the ability to generate tolerance to food and commensal bacterial antigens as well as active immune responses to pathogens (Bailey et al. 2001). Unlike the mature pig (Vega-Lopez et al. 1993; Wilson et al. 1996), which has a high extent of organisation, the cells and structures involved in mucosal immune 
responses are initially absent at birth, and preliminary studies have indicated that they populate the intestine of the young pig in a highly-programmed sequence (Bailey et al. 2005). These phenotypic studies strongly suggest that the mucosal immune system remains relatively immature throughout the 'normal commercial weaning' period. If, as postulated, the intestinal lamina propria is critically involved in determining active immune responses and tolerance in mature pigs, then it is of importance to determine the mechanisms by which this microenvironment is established and maintained in neonatal pigs and the impact of weaning and rearing environment on immunological homeostasis. The young piglet is capable of active immune responses to live virus and to dietary components by 3 weeks old, but quantitatively and qualitatively these responses differ markedly from that in older animals (Bailey et al. 2004). Early weaning at 3 weeks of age is associated with a transient reduction in the ability of intraepithelial lymphocytes to respond to mitogens and splenic T-cells to secrete IL-2 (Bailey et al. 2005). Furthermore, tolerance to fed proteins introduced at weaning is not fully achieved until 8 weeks of age (Miller et al. 1994).

The first hypothesis put forward to explain intestinal damage shortly after weaning is adverse immune responses to dietary antigens (Dréau \& Lallès, 1999). A second hypothesis is that the lack of intestinal stimulation as a result of post-weaning anorexia is a primary factor in intestinal inflammation, with responses to dietary antigens being secondary (McCracken et al. 1999). Indeed, inflammatory cytokine gene expression is transiently up regulated soon after weaning (Pié et al. 2004).

\section{Feed intake around weaning}

The post-weaning period is characterised by a marked reduction in VFI, poor growth and development, diarrhoea and an increased risk of disease, particularly from enterotoxigenic Escherichia coli (ETEC) and Salmonella. The hypothesis is that the reduction in VFI following weaning is critical in determining subsequent gut development, growth, maturation of gut-associated lymphoid tissue and related disease susceptibility (Pluske et al. 1997; van Beers-Schreurs et al. 1998; Spreeuwenberg et al. 2001; Vente Spreeuwenberg et al. 2003). A relationship between feed intake after weaning and villus height has been reported (Pluske et al. 1997) and it was speculated that this relationship may affect the overall efficiency of nutrient capture and utilisation. It is also recognised that feed intake in pigs is highly variable following weaning.

Bruininx et al. (2001) have reported a highly-variable individual VFI post weaning in group-housed pigs weaned at $27-28 \mathrm{~d}$ of age. They have suggested that this variability may be linked to weaning weight, genotype and gender. The same authors (Bruininx et al. 2002) have established a positive relationship between cumulative feed intake during days $0-3$ post weaning and villus height. However, they conclude that the physiology and function of the gut is not markedly influenced by the time between weaning and the onset of feeding or by the subsequent increase in daily food intake. Bruininx et al. (2002) have reported a minimal and variable creep intake preweaning and a highly-variable individual VFI post weaning in group-housed pigs. Interestingly, they conclude that even minimal creep feed consumption during the suckling period stimulates early post weaning VFI. English (1981) has suggested that adequate creep intake before weaning confers protection against disease. This notion is supported by a recent study showing links between creep VFI before weaning and post weaning occurrence of collibacillosis (Carstensen et al. 2005). E. coli infection is lower in piglets consuming an optimal amount of creep feed as compared with those consuming either no creep feed or high amounts before weaning. This finding illustrates the importance of VFI regulation at this period. Several factors are likely to influence VFI at weaning, including preweaning environment, age at weaning, creep feeding, mixing or stress at weaning, diet, weaning environment and health status.

\section{Managing gastrointestinal tract health of weanling piglets through the diet}

\section{Proteins and amino acids}

Dairy products are known to have a beneficial effect on VFI, growth performance, feed efficiency and health in young pigs, because of the high palatability and digestibility of protein and energy (for review, see Thacker, 1999). Intestinal villus atrophy post weaning is limited with a diet based on skimmed-milk powder as compared with feather meal (Vente-Spreeuwenberg et al. 2004a). Hydrolysing protein has no favourable effect shortly after weaning (Vente-Spreeuwenberg et al. 2004b).

Spray-dried plasma (SDP) incorporated into the diet stimulates growth performance mostly through an increase in VFI (van Dijk et al. 2001); small intestinal alterations as well as the incidence and severity of post-weaning diarrhoea are often reduced. SDP has a high palatability, which is mostly associated with the $\operatorname{IgG}$ fraction of SDP (Pierce et al. 2005). SDP as compared with fish meal and colistin in pigs challenged with ETEC favours the growth of lactobacilli in the ileum and caecum (Torrallardona et al. 2003). Part of the positive effect of SDP may be related to the action of insulin-like growth factor 1 on growth, non-Ig glycoprotein-enhanced intestinal protection against $E$. coli and improved immuno-competence through the provision of Ig (van Dijk et al. 2001). A positive beneficial effect of anti-E. coli antibodies in SDP has been demonstrated (Owusu-Asiedu et al. 2002), and SDP decreases gene expression of IL1- $\beta$, IL- 6 and TNF $\alpha$ in many organs (Touchette et al. 2002) and lowers immune cell density in the intestinal mucosa (Jiang et al. 2000). However, Van Dijk et al. (2002) have found no improved response to an $E$. coli challenge in SDP-supplemented piglets, and an immune over-response with associated increased intestinal damage has even been reported in response to a lipopolysaccharide challenge (Touchette et al. 2002). SDP has shown beneficial effects on intestinal architecture in weaned pigs challenged with E. coli (Torrallardona et al. 2003; Bosi et al. 2004). The magnitude of VFI and growth improvements is lower when SDP 
is associated with vegetable ingredients as compared with dairy ingredients (van Dijk et al. 2001). Feeding pea (Pisum sativum)-protein isolates as compared with SDP is responsible for more diarrhoea and higher mortality, increased ETEC colonisation and proliferation in the small intestine and shorter villus height (Owusu-Asiedu et al. $2003 a, b)$. All the available data support SDP as a valuable alternative to in-feed antibiotics in weaner diets.

Glutamine and glutamate are important fuels for intestinal cells. They improve growth performance and feed efficiency post weaning and limit intestinal villus atrophy (Wu et al. 1996; Ewtushick et al. 2000; Domeneghini et al. 2004, 2006). Interestingly, glutamine stimulates the division of enterocytes while decreasing apoptosis of enterocytes and lymphocytes (Domeneghini et al. 2004, 2006). It also stimulates both innate and adaptative components of immunity, as shown by increased densities of macrophages and intra-epithelial lymphocytes. Alanine and glycine have been shown to stimulate the production of the so-called anti-secretory factor, improve growth performance and reduce the incidence of diarrhoea (Goransson, 1997). This anti-secretory factor provides protection against diarrhoeal diseases and intestinal inflammation, and it has been shown to be low immediately post weaning in pigs (for review, see Lange \& Lonnroth, 2001). Arginine also prevents villus atrophy (Ewtushick et al. 2000). Cystine provided at $25 \%$ above requirements decreases jejunal mass, possibly because of its mucolytic properties (Harte et al. 2003). Finally, dietary supplementation with L-tryptophan can improve villus:crypt in the small intestine but it may depress VFI and growth (Koopmans et al. 2006).

\section{Prebiotics}

The addition of fermentable carbohydrates to the diet of weaning piglets is regarded as a comparatively straightforward way to improve microbiota composition and functionality in both the small and large intestines of piglets (Williams et al. 2001; Bauer et al. 2006).

As a simple molecule, lactose can be used as a fermentable substrate by weaned pigs, since intestinal lactase activity decreases rapidly after weaning. The magnitude of its positive effects depends on the level of incorporation of lactose and the presence of other fermentable substrates or the crude protein $(\mathrm{N} \times 6.25)$ level in the diet (Pierce et al. 2006, 2007). Small intestinal architecture is improved when inulin is added to a diet low in lactose, but it has no effect when added to a diet high in lactose. A high dietary level of lactose favours bifidobacteria and lactobacilli while decreasing E. coli (Pierce et al. 2006, 2007). Higher levels of total VFA, and particularly butyric acid, and lower levels of branched VFA are produced with high dietary levels of lactose. Thus, the positive effects of lactose-containing diets may be a result of lower protein fermentation and $\mathrm{NH}_{3}$ production with a low lactose and inulin diet. Increasing protein to $>185 \mathrm{~g} / \mathrm{kg}$ fails to stimulate growth performance at a low level of lactose but has a stimulatory effect at a higher level of lactose (Pierce et al. 2006). This effect is related to decreased protein fermentation and E. coli counts and increased VFA production, including butyrate in the colon.
Furthermore, there is also a stimulating effect on villus height in the proximal jejunum.

The composition of the bacterial community in the gut of weaning piglets is affected by the dietary addition of sugarbeet pulp, inulin, lactulose and wheat starch, a diet specifically designed to stimulate the fermentation along the entire GIT (Konstantinov et al. 2003, 2004a). Fermentable carbohydrates could enhance colonic microbial stability and diversity, with concomitant stimulation of the growth of Lactobacillus sobrius, a novel and beneficial member of the porcine commensal microbiota (Konstantinov et al. 2004a, 2006b). Similarly, it has been shown, using chaperonin-60 gene clone libraries, that Lactobacillus amylovorus-related populations, most probably $L$. sobrius, are highly abundant, although with considerable individual variation, in the ileum of weaned piglets fed either maize- barley- or wheat-based diets (Hill et al. 2005). Interestingly, the addition of inulin to different basal diets affects the proportion of piglets with detectable levels of bifidobacteria, while lactobacilli are unaffected (Loh et al. 2006). This study, however, did not discriminate between different species within groups, thus not allowing for the detection of stimulation of specific populations.

Thus, increased intake of prebiotics creates more favourable lumen conditions for gut health but direct evidence for enhanced resistance to unfavourable conditions is still lacking.

\section{Probiotics}

In the weaning period the most promising effects of the use of probiotics are related to the competitive exclusion of pathogenic bacteria. This effect could be a result of their positive influence on gut microbiota balance, intestinal epithelium integrity, appropriate maturation of the gutassociated tissue and function of the neuro-endocrine system (Metzler et al. 2005). In weaning pigs challenged with pathogens a strategy to select favourable commensal strains from the pig gut seems the more successful. A mix of four lactobacilli isolated from weaning pigs can reduce $E$. coli and anaerobe counts in the gut, and decrease diarrhoea (Huang et al. 2004). The probiotic effect of L. sobrius 001T against ETEC K88 has been examined using in vitro and in vivo approaches. Supplementation of a diet based on fermentable fibre with $L$. sobrius improves the body-weight gain of weaned pigs orally challenged with ETEC K88 and reduces ileal ETEC abundance, but it does not reduce diarrhoea (Konstantinov, 2005). Beneficial effects of this strain can also be related to its ability to counteract intestinal permeability disturbances induced by ETEC on porcine IPEC-1 intestinal cells (M Roselli, A Finamore, SR Konstantinov, MS Britti, WM de Vos, $\mathrm{H}$ Smidt and E Mengheri, unpublished results). However, after supplementation with Lactobacillus rhamnosus GG (used in human subjects) in weaning pigs orally challenged with ETEC reduced growth and a trend to more ETEC excretion in faeces has been observed (Trevisi, 2005).

A study on the interaction between intestinal physiology, dietary supplementation with the probiotic E. coli strain Nissle 1917 and ETEC challenge has recently been 
reported (Schroeder et al. 2006). Before being weaned at $21 \mathrm{~d}$ of age the piglets were creep-fed a diet with or without the probiotic supplement for $10 \mathrm{~d}$ starting at $7 \mathrm{~d}$ of age, and at 4 and $24 \mathrm{~h}$ post weaning they were challenged with ETEC. The probiotic was found to abolish diarrhoea, reduce secretagogue-induced chloride secretion at the jejunum and suppress the decreased paracellular permeability observed after ETEC challenge in nonsupplemented pigs (Schroeder et al. 2006). Many mechanisms may be involved in the intestinal epithelial cell protection by probiotics against ETEC, including competitive exclusion, reduced ETEC adhesion, maintenance of epithelial tight-junction integrity, reduced neutrophil transmigration and increased mucin gene expression, depending strongly on the probiotic strain used (Roselli et al. 2005). Administration of live yeast (Saccharomyces cerevisiae spp. boulardii) to weaned pigs for 3-4 weeks improves growth performance post weaning, villus height, epithelial cell proliferation and the numbers of macrophages at various sites of the small intestine (Baum et al. 2002; Bontempo et al. 2006). Interestingly, supplementing the sows with Escherichia faecium strongly decreases the incidence of diarrhoea in piglets in the first week post weaning (Taras et al. 2006). It also reduces the level of cytotoxic (CD8+) T-cells in the jejunal epithelium of the piglets, probably in relation with the lower frequency of $\beta$-haemolytic and O141 serovars of E. coli (Scharek et al. 2005).

\section{Dietary fibre and colibacillosis in weaned piglets}

Australian studies (Hopwood \& Hampson, 2003) have provided the basis for dietary management of important enteric infectious diseases in pigs, including swine dysentery, intestinal spirochaetosis and gastric ulceration; the main conclusion being that to reduce the proliferation of associated pathogens diets should be low in soluble NSP and/or resistant starch. However, a recent Danish study (Lindecrona et al. 2003) has failed to confirm these observations. The conclusion of the Australian studies (Hopwood \& Hampson 2003, Hopwood et al. 2004) is that post-weaning colibacillosis is influenced by dietary components, especially NSP, which generates high viscosity of intestinal contents. Viscous carboxymethylcellulose has been shown to favour post-weaning colibacillosis in piglets when incorporated into a diet based on cooked white rice and animal protein, which is itself considered to be protective to the GIT (McDonald et al. 2001). However, this model substance associated with skimmed milk and maltodextrin reveals a relatively protective effect on the intestine of weaned pigs (Lallès et al. 2006; Piel et al. 2005). Thus, carboxymethylcellulose may impact positively on the gut depending on circumstances. Replacing animal proteins with plant protein sources in a cooked white rice protective diet (McDonald et al. 2001) does not increase the risk of post weaning colibacillosis (Montagne et al. 2004).

On the other hand, pearl barley rich in $\beta$-glucans increases digesta viscosity and exacerbates post-weaning colibacillosis and diarrhoea (Hopwood et al. 2004). In contrast, $\beta$-glucans from lentinan (from Lentinus edodes) stimulate jejunal villus length and villus height:crypt depth, possibly as a result of depressed bacterial load (Van Nevel et al. 2003). Other sources of non-digestible oligosaccharides include guar gum, locust bean gum (which is extracted from carob tree (Ceratonia siliqua) seeds) and carob tree seeds, of which carob tree seeds have been shown to have the more marked effects, reducing villus height and increasing crypt depth in the proximal jejunum (Van Nevel et al. 2005). Locust bean gum decreases the numbers of lactobacilli in the stomach and jejunum, while carob tree seeds increase $E$. coli counts in the contents and mucosa of the distal jejunum (Van Nevel et al. 2005). Phosphorylated mannans derived from yeast (Saccharomyces cerevisiae) cell wall stimulate phagocytosis of intestinal macrophages and increase the proportion of CD8 + T lymphocytes in the jejunal lamina propria, in addition to improving growth performance (Davis et al. 2004).

\section{Other substances}

Natural plant or herbal extracts are yet another potential viable alternative to traditional antimicrobials. Isoflavone phyto-oestrogens have been shown to affect performance, physiology and gut microbiota of farm animals (for review, see Han et al. 2006). Interestingly, administration of daidzein causes an increase in the relative abundance of lactobacilli in in vitro fermentation assays (Yao et al. 2004). A mixture of carvacrol, cinnamaldehyde and capsicum oleoresin, given at increasing doses to piglets from $12 \mathrm{~d}$ post weaning, linearly increases intestinal lactobacilli as well as lactobacilli:enterobacteria (Manzanilla et al. 2004). Similarly, an extract containing cinnamon (Cinnamomum zeylandica), thyme (Thymus vulgaris L.) and oregano (Origanum vulgare L.) extract reduces the growth of coliforms (Namkung et al. 2004). Curiously, little information is available on the effect of antioxidants on the GIT of weaning pigs despite the body of literature existing on the protective properties of such substances (e.g. antioxidants from tea; Asfar et al. 2003).

\section{Conclusions and perspectives}

The weaning period in pigs is complex and its nutritional control is not easy to achieve. However, important progress has been made in understanding this complexity at the GIT level, with reference to the physiology, microbiota and local immune system. Based on this knowledge, stimulating beneficial bacteria and (or) bacterial metabolites through the consumption of fermentable carbohydrates (prebiotics) in the diet is clearly one major option. Recent studies of the effects of some probiotics on GIT health also look promising, but the responses show strain specificity. By contrast, there is still the need for a basic knowledge of the development of mucosal immunity in order to envisage practical nutritional approaches to control the regulator and effector arms of immune responses.

Future investigations should be directed towards: understanding the intimate interactions between microbiota, mucosal physiology and immunity; systematic 
quantitative assessment of GIT microbiota requirements for fermentable carbohydrates at various GIT sites; definition of optimal combinations of simple and complex prebiotics together with other dietary components that maximise animal performance and health; evaluation of the impact of such diets balanced for microbiota requirements on piglet susceptibility to GIT disorders and enteric infections. Finally, many other substances of plant origin have the potential to contribute to GIT health around weaning. However, more convincing data and mechanistic interpretations are needed before these substances can be considered for inclusion in commercial diets.

\section{Acknowledgements}

The authors acknowledge the EU for financial support for research in gut health and nutrition in piglets around weaning (Healthypigut project no. QLK5-CT2000-00522 and Feed for Pig Health project no. FP6-Food-1-506144).

\section{References}

Asfar S, Abdeen S, Dashti H, Khourshedd M, Al-Sayer H, Mathew T \& Al-Bader A (2003) Effect of green tea in the prevention and reversal of fasting-induced intestinal mucosal damage. Nutrition 19, 536-540.

Bailey M, Haverson K, Inman C, Harris C, Jones P, Corfield G, Miller B \& Stokes C (2005) The development of the mucosal immune system pre- and post-weaning: balancing regulatory and effector function. Proceedings of the Nutrition Society 64 , 451-457.

Bailey M, Haverson K, Miller B, Jones P, Sola I, Enjuanes L \& Stokes CR (2004) Effects of infection with transmissible gastroenteritis virus on concomitant immune responses to dietary and injected antigens. Clinical Diagnostic and Laboratory Immunology 11, 337-343.

Bailey M, Plunkett FJ, Rothkotter H-J, Vega-Lopez MA, Haverson K \& Stokes CR (2001) Regulation of mucosal immune responses in effector sites. Proceedings of the Nutrition Society 60, 427-435.

Bauer E, Williams BA, Smidt H, Mosenthin R \& Verstegen MWA (2006) Influence of dietary components on development of the microbiota in single-stomached species. Nutrition Research Reviews 19, 1-17.

Baum B, Liebler-Tenorio EM, Enss ML, Pohlenz JF \& Breves G (2002) Saccharomyces $L$ and Bacillus cereus var. Toyoi influence the morphology and the mucins of the intestine of pigs. Zeitschrift für Gastroenterologie 40, 277-284.

Bontempo V, Di Giancamillo A, Savoini G, Dell'Orto V \& Domeneghini C (2006) Live yeast dietary supplementation acts upon intestinal morpho-functional aspects and growth in weanling piglets. Animal Feed Science and Technology 129, 224-236.

Bosi P, Casini L, Finamore A, Cremokolini C, Merialdi G, Trevisi P, Nobili F \& Mengheri E (2004) Spray-dried plasma improves growth performance and reduces inflammatory status of weaned pigs challenged with enterotoxigenic Escherichia coli K88. Journal of Animal Science 82, 1764-1772.

Boudry G, Péron V, Le Huérou-Luron I, Lallès JP \& Sève B (2004) Weaning induces both transient and long-lasting modifications of absorptive, secretory, and barrier properties of piglet intestine. Journal of Nutrition 134, 2256-2262.

Brooks PH, Moran CA, Beal JD, Demeckova V \& Campbell A (2001) Liquid feeding for the young piglet. In The Weaner
Pig: Nutrition and Management, pp. 153-178 [MA Varley and J Wiseman, editors]. Wallingford, Oxon: CAB International.

Bruininx EM, Binnendijk GP, van der Peet-Schwering CM, Schrama JW, den Hartog LA, Everts H \& Beynen AC (2002) Effect of creep feed consumption on individual feed intake characteristics and performance of group-housed weanling pigs. Journal of Animal Science 80, 1413-1418.

Bruininx EM, van der Peet-Schwering CM, Schrama JW, Vereijken PF, Vesseur PC, Everts H, den Hartog LA \& Beynen AC (2001) Individually measured feed intake characteristics and growth performance of group-housed weanling pigs: effects of sex, initial body weight, and body weight distribution within groups. Journal of Animal Science 79, 301-308.

Butler JE, Sun J, Weber P, Navarro P \& Francis D (2000) Antibody repertoire development in fetal and newborn piglets, III. Colonization of the gastrointestinal tract selectively diversifies the preimmune repertoire in mucosal lymphoid tissues. Immunology 100, 119-130.

Carstensen L, Ersboll AK, Jensen KH \& Nielsen JP (2005) Escherichia coli post-weaning diarrhoea occurrence in piglets with monitored exposure to creep feed. Veterinary Microbiology 110, 113-123.

Davis ME, Maxwell CV, Erf GF, Brown DC \& Wistuba TJ (2004) Dietary supplementation with phosphorylated mannans improves growth response and modulates immune function of weanling pigs. Journal of Animal Science 82, 1882-1891.

Decuypere JA \& Dierick NA (2003) The combined use of triacylglycerols containing medium-chain fatty acids and exogenous lipolytic enzymes as an alternative to in-feed antibiotics in piglets: concept, possibilities and limitations. An overview. Nutrition Research Reviews 16, 193-209.

Domeneghini C, Di Giancamillo A, Bosi G \& Arrighi S (2006) Can nutraceuticals affect the structure of intestinal mucosa? Qualitative and quantitative microanatomy in L-glutamine diet-supplemented weaning piglets. Veterinary Research Communications 30, 331-342.

Domeneghini C, Di Giancamillo A, Savoini G, Paratte R, Bontempo V \& Dell'Orto V (2004) Structural patterns of swine ileal mucosa following L-glutamine and nucleotide administration during the weaning period. An histochemical and histometrical study. Histology and Histopathology 19, 49-58.

Dréau D \& Lallès JP (1999) Contribution to the study of gut hypersensitivity reactions to soybean proteins in preruminant calves and early-weaned piglets. Livestock Production Science 60, 209-218.

English PR (1981) Establishing the early weaned pig. Proceedings of the Pig Veterinary Society 7, 29-37.

Ewtushick AL, Bertolo RFP \& Ball RO (2000) Intestinal development of early-weaned piglets receiving diets supplemented with selected amino acids or polyamines. Canadian Journal of Animal Science 80, 653-662.

Goransson L (1997) Alternatives to antibiotics - The influence of new feeding strategies for pigs on biology and performance. In Recent Advances in Animal Nutrition, pp. 45-56 [PC Garnsworthy and J Wiseman, editors]. Nottingham: Nottingham University Press.

Han ZK, Wang GJ, Yao W \& Zhu WY (2006) Isoflavonic phytoestrogens - new prebiotics for farm animals: a review on research in China. Current Issues in Intestinal Microbiology $\mathbf{7}$, 53-60.

Harte RD, Shoveller AK, Bertolo RFP \& Ball RO (2003) Cystine supplementation adversely affects small intestinal morphology. In Proceedings of the 9th International Symposium on Digestive Physiology in Pigs, pp. 213-215 [RA Ball, editor]. Banff, Alberta: University of Alberta Publisher.

Hill JE, Hemmingsen SM, Goldade BG, Dumonceaux TJ, Klassen J, Zijlstra RT, Goh SH \& Van Kessel, AG (2005) 
Comparison of ileum microflora of pigs fed corn-, wheat-, or barley-based diets by chaperonin-60 sequencing and quantitative PCR. Applied and Environmental Microbiology 71, 867-875.

Hopwood DE \& Hampson DJ (2003) Interactions between the intestinal microflora, diet and diarrhoea, and their influences on piglet health in the immediate post-weaning period. In Weaning the Pig: Concepts and Consequences, pp. 199-217 [JR Pluske, J Le Dividich and MWA Verstegen, editors]. Wageningen, The Netherlands: Wageningen Academic Publishers.

Hopwood DE, Pethick DW, Pluske JR \& Hampson DJ (2004) Addition of pearl barley to a rice-based diet for newly weaned piglets increases the viscosity of the intestinal contents, reduces starch digestibility and exacerbates post-weaning colibacillosis. British Journal of Nutrition 92, 419-427.

Huang C, Qiao S, Lifa D, Piao X \& Ren J (2004) Effects of lactobacilli on the performance, diarrhea incidence, VFA concentration and gastrointestinal microbial flora of weaning pigs. Asian-Australasian Journal of Animal Science 17, 401-409.

Inoue R, Tsukahara T, Nakanishi N \& Ushida K (2005) Development of the intestinal microbiota in the piglet. Journal of General and Applied Microbiology 51, 257-265.

Jiang R, Chang X, Stoll B, Fan MZ, Arthington J, Weaver E, Campbell \& Burrin DG (2000) Dietary plasma protein reduces small intestinal growth and lamina propria cell density in early weaned pigs. Journal of Nutrition 130, 21-26.

Konstantinov SR (2005) From composition to functionality of the porcine intestinal microbiota. $\mathrm{PhD}$ Thesis, Wageningen University, The Netherlands.

Konstantinov SR, Awati A, Smidt H, Williams BA, Akkermans ADL \& de Vos WM (2004a) Specific response of a novel and abundant Lactobacillus amylovorus-like phylotype to dietary prebiotics in the ileum and colon of weaning piglets. Applied Environmental Microbiology 70, 3821-3830.

Konstantinov SR, Awati AA, Williams BA, Miller BG, Jones P, Stokes CR, Akkermans ADL, Smidt H \& de Vos WM (2006ab) Post-natal development of the porcine microbiota composition and activities. Environmental Microbiology 8, 1191-1199.

Konstantinov SR, Favier CF, Zhu WY, Williams BA, Klüss J, Souffrant WB, de Vos WM, Akkermans ADL \& Smidt H (2004b) Microbial diversity studies of the porcine gastrointestinal ecosystem during weaning transition. Animal Research 53, 317-324.

Konstantinov SR, Poznanski E, Fuentes S, Akkermans ADL, Smidt H \& de Vos WM (2006ba) Lactobacillus sobrius sp. nov., a novel isolate abundant in the intestine of weaning piglets. International Journal of Systematic and Evolutionary Microbiology 56, 29-32.

Konstantinov SR, Zhu WY, Williams BA, Tamminga S, de Vos WM \& Akkermans ADL (2003) Effect of fermentable carbohydrates on faecal bacterial communities as revealed by DGGE analysis of 16S rDNA. FEMS Microbiology Ecology 43, 225-235.

Koopmans SJ, Guzik AC, van der Meulen J, Dekker R, Kogut J, Kerr BJ \& Southern LL (2006) Effects of supplemental Ltryptophan on serotonin, cortisol, intestinal integrity, and behavior in weanling piglets. Journal of Animal Science 84, 963-971.

Lallès JP, Boudry G, Favier C, Le Floc'h N, Luron I, Montagne L, Oswald IP, Pié S, Piel C \& Sève B (2004) Gut function and dysfunction in young pigs: physiology. Animal Research 53, 301-316.

Lallès JP, Boudry G, Favier C \& Sève B (2006) High-viscosity carboxymethylcellulose reduces carbachol-stimulated intestinal chloride secretion in weaned piglets fed a diet based on skimmed milk powder and maltodextrin. British Journal of Nutrition 95, 488-495.

Lange S \& Lonnroth I (2001) The anti-secretory factor: synthesis, anatomical and cellular distribution, and biological action in experimental and clinical studies. International Review of Cytology 210, 39-75.

Le Dividich J \& Sève B (2000) Effects of underfeeding during the weaning period on growth, metabolism, and hormonal adjustments in the piglet. Domestic Animal Endocrinology 19, 63-74.

Lindecrona RH, Jensen TK, Jensen BB, Leser TD, Jiufeng W \& Moller K (2003) The influence of diet on the development of swine dysentery upon experimental infection. Animal Science 76, 81-87.

Loh G, Eberhard M, Brunner RM, Hennig U, Kuhla S, Kleessen B \& Metges CC (2006) Inulin alters the intestinal microbiota and short-chain fatty acid concentrations in growing pigs regardless of their basal diet. Journal of Nutrition 136, 1198-1202.

McCracken BA, Spurlock ME, Roos MA, Zuckermann FA \& Gaskins HR (1999) Weaning anorexia may contribute to local inflammation in the piglet small intestine. Journal of Nutrition 129, 613-619.

McDonald DE, Pethick DW, Mullan BP \& Hampson DJ (2001) Increasing viscosity of the intestinal contents alters small intestinal structure and intestinal growth, and stimulates proliferation of enterotoxigenic Escherichia coli in newlyweaned pigs. British Journal of Nutrition 86, 487-498.

MacFarlane GT, Gibson GR, Beatty E \& Cummings JH (1992) Estimation of short-chain fatty acid production from protein by human intestinal bacteria based on branched-chain fatty acid measurements. FEMS Microbiology Ecology 101, 819-822.

Manzanilla EG, Perez JF, Martin M, Kamel C, Baucells F \& Gasa J (2004) Effect of plant extracts and formic acid on the intestinal equilibrium of early-weaned pigs. Journal of Animal Science 82, 3210-3218.

Metzler B, Bauer E \& Mosenthin R (2005). Microflora management in the gastrointestinal tract of piglets. Asian-Australasian Journal of Animal Science 18, 1353-1362.

Miller BG, Whittemore CT, Stokes CR \& Telemo E (1994) The effect of delayed weaning on the development of oral tolerance to soya-bean protein in pigs. British Journal of Nutrition 71, 615-625.

Montagne L, Cavaney FS, Hampson DJ, Lallès JP \& Pluske JR (2004) Effect of diet composition on postweaning colibacillosis in piglets. Journal of Animal Science 82, 2364-2374.

Mroz Z (2003) Organic acids of various origin and physicochemical forms as potential alternatives to antibiotic growth promoters for pigs. In Proceedings of the 9th International Symposium on Digestive Physiology in Pigs, vol. 1, pp. 267-293 [RA Ball, editor]. Banff, Alberta: University of Alberta Publisher.

Namkung H, Li M, Gong J, Yu H, Cottrill M \& de Lange CFM (2004) Impact of feeding blends of organic acids and herbal extracts on growth performance, gut microbiota and digestive function in newly weaned pigs. Canadian Journal of Animal Science 84, 697-704.

Owusu-Asiedu A, Baidoo SK, Nyachoti CM \& Marquardt RR (2002) Response of early-weaned pigs to spray-dried porcine or animal plasma-based diets supplemented with egg-yolk antibodies against enterotoxigenic Escherichia coli. Journal of Animal Science 80, 2895-2903.

Owusu-Asiedu A, Nyachoti CM, Baidoo SK, Marquardt RR \& Yang X (2003a) Response of early-weaned pigs to an enterotoxigenic Escherichia coli (K88) challenge when fed diets containing spray-dried porcine plasma or pea protein 
isolate plus egg yolk antibody. Journal of Animal Science 81, 1781-1789.

Owusu-Asiedu A, Nyachoti CM \& Marquardt RR (2003b) Response of early-weaned pigs to an enterotoxigenic Escherichia coli (K88) challenge when fed diets containing spray-dried porcine plasma or pea protein isolate plus egg yolk antibody, zinc oxide, fumaric acid, or antibiotic. Journal of Animal Science 81, 1790-1798.

Pié S, Lallès JP, Blazy F, Laffitte J, Sève B \& Oswald IP (2004) Weaning is associated with an upregulation of expression of inflammatory cytokines in the intestine of piglets. Journal of Nutrition 134, 641-647.

Piel C, Montagne L, Sève B \& Lallès JP (2005) Increasing digesta viscosity using carboxymethylcellulose in weaned piglets stimulates ileal goblet cell numbers and maturation. Journal of Nutrition 135, 86-91.

Pierce JL, Cromwell GL, Lindemann MD, Russell LE \& Weaver EM (2005) Effects of spray-dried animal plasma and immunoglobulins on performance of early weaned pigs. Journal of Animal Science 83, 2876-2885.

Pierce KM, Callan JJ, McCarthy P \& O'Doherty JV (2007) The interaction between lactose level and crude protein concentration on piglet post-weaning performance, nitrogen metabolism, selected faecal microbial populations and faecal volatile fatty acid concentrations. Animal Feed Science and Technology 132, 267-282.

Pierce KM, Sweeney T, Brophy PO, Callan JJ, Fitzpatrick E, McCarthy P \& O'Doherty JV (2006) The effect of lactose and inulin on intestinal morphology, selected microbial populations and volatile fatty acid concentrations in the gastrointestinal tract of the weaned pig. Animal Science 82, 311-318.

Pluske JR, Hampson DJ \& Williams IH (1997) Factors influencing the structure and function of the small intestine in the weaned pig: a review. Livestock Production Science 51, 215-236.

Roselli M, Finamore A, Britti MS, Bosi P, Oswald IP \& Mengheri E (2005) Alternatives to in-feed antibiotics in pigs: Evaluation of probiotics, zinc or organic acids as protective agents for the intestinal mucosa. A comparison of in vitro and in vivo results. Animal Research 54, 203-218.

Russell JB, Sniffen CJ \& Van SOest PJ (1983) Effect of carbohydrate limitation on degradation and utilization of casein by mixed rumen bacteria. Journal of Dairy Science 66, 763-775.

Scharek L, Guth J, Reiter K, Weyrauch KD, Taras D, Schwerk P, Schierack P, Schmidt MF, Wieler LH \& Tedin K (2005) Influence of a probiotic Enterococcus faecium strain on development of the immune system of sows and piglets. Veterinary Immunology and Immunopathology 105, 151-161.

Schroeder B, Duncker S, Barth S, Bauerfeind R, Gruber AD, Deppenmeier S \& Breves G (2006) Preventive effects of the probiotic Escherichia coli strain Nissle 1917 on acute secretory diarrhea in a pig model of intestinal infection. Digestive Disease and Science 51, 724-731.

Spreeuwenberg MAM, Verdonk JMAJ, Gaskins HR \& Verstegen MWA (2001) Small intestine epithelial barrier function is compromised in pigs with low feed intake at weaning. Journal of Nutrition 131, 1520-1527.

Taras D, Vahjen W, Macha M \& Simon O (2006) Performance, diarrhea incidence, and occurrence of Escherichia coli virulence genes during long-term administration of a probiotic Enterococcus faecium strain to sows and piglets. Journal of Animal Science 84, 608-617.

Thacker PA (1999) Nutritional requirements of early weaned pigs: a review. Pig News Information 20, 13N-24N.

Torrallardona D, Conde MR, Badiola I, Polo J \& Brufau J (2003) Effect of fishmeal replacement with spray-dried animal plasma and colistin on intestinal structure, intestinal microbiology, and performance of weanling pigs challenged with Escherichia coli K99. Journal of Animal Science 81, 1220-1226.

Touchette KJ, Carroll JA, Allee GL, Matteri RL, Dyer CJ, Beausang LA \& Zannelli ME (2002) Effect of spray-dried plasma and lipopolysaccharide exposure on weaned pigs: I. Effects on the immune axis of weaned pigs. Journal of Animal Science 80, 494-501.

Trevisi P (2005) Effetto di differenti scelte dietetiche ad azione pre e probiotica sulle prestazioni di crescita, lo stato di salute, la risposta immunitaria umorale e lo sviluppo funzionale dell'intestino tenue del suino in svezzamento (Effect of different dietary solutions with pre- and probiotic actions, on growth performance, health, humoral immune response and functional development of small intestine of weaning pig). $\mathrm{PhD}$ Thesis, University of Bologna, Italy.

Van Beers-Schreurs HM, Nabuurs MJ, Vellenga L, Kalsbeek-van der Valk HJ, Wensing T \& Breukink HJ (1998) Weaning and the weanling diet influence the villous height and crypt depth in the small intestine of pigs and alter the concentrations of short-chain fatty acids in the large intestine and blood. Journal of Nutrition 128, 947-953.

Van der Waaij D, Berghuis-de Vries JM \& Lekkerkerk-van der Wees JEC (1971) Colonization resistance of the digestive tract in conventional and antibiotic-treated mice. Journal of Hygiene (London) 69, 405-411.

Van Dijk AJ, Enthoven PMM, Van den Hoven SGC, Van Laarhoven MMMH, Niewold TA, Nabuurs MJA \& Beynen AC (2002) The effect of dietary spray-dried porcine plasma on clinical response in weaned piglets challenged with a pathogenic Escherichia coli. Veterinary Microbiology, 84, 207-218.

Van Dijk AJ, Everts H, Nabuurs NJA, Margry RJCF \& Beynen AC (2001) Growth performance of weaned pigs fed spraydried animal plasma: a review. Livestock Production Science 68, 263-274.

Van Nevel CJ, Decuypere JA, Dierick N \& Molly K (2003) The influence of Lentinus edodes (Shiitake mushroom) preparations on bacteriological and morphological aspects of the small intestine in piglets. Archives für Tierernahrung 57, 399-412.

Van Nevel CJ, Decuypere JA, Dierick NA \& Molly K (2005) Incorporation of galactomannans in the diet of newly weaned piglets: effect on bacteriological and some morphological characteristics of the small intestine. Archives of Animal Nutrition 59, 123-138.

Vega-Lopez MA, Telemo E, Bailey M, Stevens K \& Stokes CR (1993) Immune cell distribution in the small-intestine of the pig - immunohistological evidence for an organized compartmentalization in the lamina propria. Veterinary Immunology and Immunopathology 37, 49-60.

Vente-Spreeuwenberg MAM, Verdonk JMAJ, Bakker GCM, Beynen AC \& Verstegen MWA (2004a) Effect of dietary protein source on feed intake and small intestinal morphology in newly weaned piglets. Livestock Production Science 86, 169-177.

Vente-Spreeuwenberg MAM, Verdonk JMAJ, Koeninkx JFJG, Beynen AC \& Verstegen MWA (2004b) Dietary protein hydrolysates vs. intact proteins do not enhance mucosal integrity and growth performance in weaned piglets. Livestock Production Science 85, 151-164.

Vente-Spreeuwenberg MAM, Verdonk JMAJ, Verstegen MWA \& Beynen AC (2003) Villus height and gut development in weaned piglets receiving diets containing either glucose, lactose or starch. British Journal of Nutrition 90, 907-913.

Visek WJ (1978) Diet and cell growth modulation by ammonia. American Journal of Clinical Nutrition 31, S216-S220. 
Williams BA, Verstegen MWA \& Tamminga S (2001) Fermentation in the monogastric large intestine: its relation to animal health. Nutrition Research Reviews 14, 207-227.

Wilson AD, Haverson K, Southgate K, Bland PW, Stokes CR \& Bailey M (1996) Expression of major histocompatibility complex class II antigens on normal porcine intestinal endothelium. Immunology 88, 98-103.

Wu G, Meier SA \& Knabe DA (1996) Dietary glutamine supplementation prevents jejunal atrophy in weaned pigs. Journal of Nutrition 126, 2578-2584.

Yao W, Zhu WY, Han ZK, Williams B, Tamminga S \& Akkermans ADL (2004) Daidzein increased the density but not composition of Lactobacillus community in piglet digesta during in vitro fermentation as revealed by DGGE and dilution PCR. Reproduction, Nutrition, Development 44, Suppl., S17.

Yokoyama MT, Tabori C, Miller ER \& Hogberg MG (1982) The effects of antibiotics in the weanling pig diet on growth and the excretion of volatile phenolic and aromatic bacterial metabolites. American Journal of Clinical Nutrition 35, 1417-1424.

Zoetendal EG, Collier CT, Koike S, Mackie RI \& Gaskins HR (2004) Molecular ecological analysis of the gastrointestinal microbiota: A review. Journal of Nutrition 134, 465-472. 